\title{
Validated Stability Indicating RP-HPLC Method for Simultaneous Estimation of Ofloxacin and Cefixime in their Combined Dosage Form
}

\author{
Nivrati Jain, Harshita Jain and Prateek Jain* \\ Pharmaceutical chemistry Division, Adina Institute of Pharmaceutical Sciences, Sagar-470002, \\ Bhopal Road, Madhya Pradesh, India
}

\begin{tabular}{|c|c|}
\hline Abstract & Article Information \\
\hline \multirow{3}{*}{$\begin{array}{l}\text { The objective of the current study was to develop and validate a simple, accurate, precise } \\
\text { and selective stability-indicating gradient reverse phase high performance liquid } \\
\text { chromatographic method for simultaneous estimation of Ofloxacin and Cefixime in } \\
\text { pharmaceutical formulation in presence of degradation products. The chromatographic } \\
\text { separation of Ofloxacin and Cefixime was achieved on Shimadzu LC-20AT series HPLC } \\
\text { having C18-ODS bonded column }\left(250 \times 4.6 \mathrm{~mm}, 40^{\circ} \mathrm{C}, 10 \mu \mathrm{L}\right) \text { using UV/Visible detector at } \\
276 \mathrm{~nm} \text {. The optimized mobile phase was consisted of a methanol: phosphate buffer } \\
(50: 50) \text { at a flow rate of } 1.0 \mathrm{ml} / \mathrm{m} \text {. The retention times were } 4.799 \text { and } 1.602 \mathrm{~m} \text { for Ofloxacin } \\
\text { and Cefixime respectively. The proposed method provided linear responses within the } \\
\text { concentration ranges } 5-25 \mu \mathrm{g} / \mathrm{ml} \text { for Ofloxacin and Cefixime both. The limit of detection } \\
(\mathrm{LOD}) \text { and limit of quantification (LOQ) values were found to be } 0.0259,0.078 \mu \mathrm{g} / \mathrm{ml} \text { and } \\
0.0206,0.062 \mu \mathrm{m} / \mathrm{ml} \text { for Ofloxacin and Cefixime F respectively. The developed method was } \\
\text { validated as per ICH guidelines with respect to specificity, linearity, accuracy, precision, } \\
\text { robustness and ruggedness. The studies data revealed that developed method was } \\
\text { convenient, fairly reliable, sensitive, less expensive and reproducible. } \\
\text { Copyright@2014 STAR Journal. All Rights Reserved. }\end{array}$} & \begin{tabular}{l}
\multicolumn{2}{l}{ Article History: } \\
Received $: 15-09-2014$ \\
Revised $: 30-11-2014$ \\
Accepted $: 13-12-2014$
\end{tabular} \\
\hline & legradation \\
\hline & $\begin{array}{l}{ }^{*} \text { Corresponding AL } \\
\text { Prateek Jain }\end{array}$ \\
\hline
\end{tabular}

\section{INTRODUCTION}

Ofloxacin (OFL) are wide spectrum quinolones and Cefixime (CEF) is a third-generation cephalosporin with a wider spectrum of activity against gram-positive and gram-negative bacteria and anaerobics (Ozyüncü et al., 2010). OFL chemically is a fluorinated carboxy quinolone, is a racemate, $( \pm)$ - 9-fluro-2, 3-dihydro-3-methyl-104-methyl-1-piperazinyl)-7-oxo-7H-pyrido[1,2,3-de]-1,4-ben zoxazine- 6-carboxylic acid (Figure 1A) that is active against both Gram-positive and Gram-negative bacteria. It is mainly used for the treatment of urinary tract infection and sexually transmitted diseases and also are good candidates for the development of more powerful treatment of leprosy (Chopra et al., 2001 and Veziris et al., 2013). OFL is a fluoroquinolone antibiotic with activity against various micro-organisms causing Acute exacerbation of chronic obstructive pulmonary disease (AECOPD) (Yoon etal., 2013). It inhibits DNA gyrase, a type II topoisomerase, and topoisomerase IV. CEF is chemically known as $(6 R, 7 R)-7-\{[2-(2$-amino-1,3-thiazol4-yl)2(carboxymethoxyimino) acetyl]amino\}-3-ethenyl-8oxo-5-thia-1-azabicyclo[4.2.0] oct-2-ene-2-carboxylic acid (Figure 1B) (Ali Ahmed et al., 2013). CEF is the extendedspectrum cephalosporins, are currently the recommended first-line antimicrobials in most countries worldwide, can be used for the treatment of gonorrhea as an empirical first-line therapy (Sethi et al., 2013 and Olsen et al., 2013). Synthesis of cell wall inhibit by the bactericidal action of cephalosporin, which inhibits the final transpeptidation step of the peptidoglycan synthesis in the bacterial cell wall, thus inhibiting biosynthesis of cell wall assembly by arresting, resulting in bacterial cell death.

Elbashir et al., 2012, Khan et al., 2011, Nemutlu et al., 2009, Pulgarín et al., 2013, Hubicka et al., 2013, Lalitha Devi et al., 2009, Patel et al., 2011, Shervington et al., 2005 and Deekonda et al., 2014 reported various analytical methods, like RP-HPLC/UV detection method, Spectrofluorimetric method, Capillary Electrophoresis, UPLC-MS/MS. Validated stability-indicating RP-HPLC methods have been already reported. Fixed dose combination of a fluoroquinolone antibiotic $(200 \mathrm{mg})$ and an antimicrobial agent CEF (200 mg) would take care of both the components of antimicrobial which give greater clinical efficacy. The present article introduces a simple, specific, precise and rapid RP- HPLC method for simultaneous estimation of OFL and CEF in combined dosage form. The developed method is further validated and from the validation study, it was found that the method is specific, accurate, precise, and reproducible.
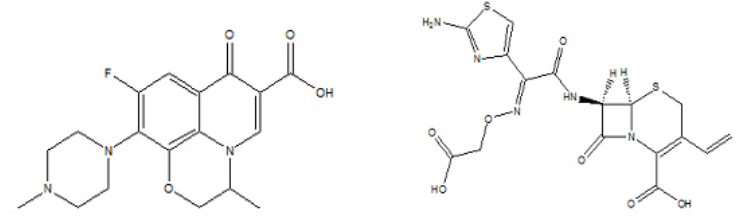

Figure 1: Chemical structure of (A) OFL and (B) CEF. 


\section{MATERIALS AND METHODS}

\section{Instrumentation}

The HPLC system consisted of a model LC-20AT (Prominence) Shimadzu, Japan was used having UV (SPD-20A)Prominence UV/Visible detector. Column Phenomenex Gemini C18 -ODS bonded column of length $250 \mathrm{~mm}$ and an inter diameter $4.6 \mathrm{~mm}$ was selected for analysis. The particle size of the stationary phase was $5 \mu$. The Mobile phase was a degassed and filtered $(0.45 \mu \mathrm{m}$, Millipore, Watford, UK) methanol: phosphate buffer (50:50) Flow rate $1 \mathrm{ml} / \mathrm{m}$. Frontline Ultra Sonic Cleaner Fs-10 Sonicator was used for sonication The column temperature was maintained at $40^{\circ} \mathrm{C}$ using a model 7716 HPLC column block heater CTO-20AC.

\section{Material}

The gift samples of drugs i.e. OFL and CEF was provided by Anupam biotech, Manpur, Bhind, India and was confirmed by the official methods. Methanol, phosphate buffer and all other chemicals were purchased from Himedia labs Mumbai. All the chemicals of HPLC and analytical grades and used without any further purification.

\section{Standard Solution Preparation}

Methanol: Phosphate buffer (50:50) was used as diluent. The stock solutions of OFL and CEF $(1000 \mu \mathrm{g} / \mathrm{ml}$ of both) were prepared by dissolving an appropriate amount of analyte in diluent, separately. Working standard solution was prepared in diluent from mixing above stock solutions of OFL and CEF with final concentration of $100 \mu \mathrm{g} / \mathrm{ml}$.

\section{Sample Solution Preparation}

Tablet powder equivalent to $100 \mathrm{mg}$ of OFL and CEF was transferred into $100 \mathrm{ml}$ volumetric flask, added $35 \mathrm{ml}$ of diluent and ultrasonicated for $20 \mathrm{~m}$, and then diluted to volume with diluent. This solution was further diluted with diluent to give a solution containing $100 \mu \mathrm{g} / \mathrm{ml}$ of OFL and CEF each.

\section{Analysis of Tablet Formulation}

Twenty tablets were weighed accurately, and a quantity of tablet powder equivalent to $200 \mathrm{mg}$ OFL and $200 \mathrm{mg}$ CEF was weighed and aliquate of concentration $10 \mu \mathrm{g} / \mathrm{ml}$ was formed with mobile phase, ultrasonicated for $5 \mathrm{~m}$. The solution was filtered through Whatman (Florham Park, NJ) No. 41 paper. The tablet sample solution was injected, the chromatogram was obtained, and the peak areas were recorded.

\section{Validation of the Method \\ System Suitability}

System suitability was determined before sample analysis from six replicate injections of the standard solution containing $10 \mu \mathrm{g} / \mathrm{ml}$ of OFL and CEF each in methanol: phosphate buffer $(50: 50)$ into the chromatograph to determine peak areas, retention times $(t R)$ and chromatographic relative standard deviation (\%RSD). The retention factor $(k)$, theoretical plates $(N)$, tailing $(T f)$ and peak asymmetry $(A s)$ chromatographic parameters were also evaluated.

\section{Selectivity and Specificity}

The specificity is performed to check ability of method to measure the analyte accurately and specifically in presence of other components or drugs. The other compound should not interfere with drug and should be estimated separately.

\section{Linearity, Concentration Range, Limits of Detection and Quantitation}

Linearity test solutions were prepared by diluting the stock solutions to the required concentrations. The solutions were prepared in mobile phase at six concentration levels from $5-25 \mu \mathrm{g} / \mathrm{ml}$ for OFL and CEF both. Calibration curves were plotted between the responses of peak versus analyte concentrations. The coefficient correlation, slope, y-intercept of the calibration curve and $\%$ bias at $100 \%$ response are reported. For LOD and LOQ, $1 \mu \mathrm{g} / \mathrm{ml}$ of solution of drugs was prepared from standard stock solution of $100 \mu \mathrm{g} / \mathrm{ml}$ by diluting appropriate volume with mobile phase. Five standard solutions for CEF $0.02,0.04,0.06,0.08$ and $0.10 \mu \mathrm{g} / \mathrm{ml}$ and for OFL 0.05, 0.06, 0.07, 0.08, 0.09 and $0.10 \mu \mathrm{g} / \mathrm{ml}$ were prepared in mobile phase from $1 \mu \mathrm{g} / \mathrm{ml}$ of solution, area was noted. The LOD and LOQ of OFL and CEF by proposed methods were determined using calibration standards.

\section{Precision and Accuracy}

The intra-day precision and accuracy for the proposed method were studied at five concentration levels for each compound using three replicate determinations for each concentration within one day. Similarly, the inter-day precision and accuracy were tested by analyzing the same three concentrations for each compound using three replicate determinations repeated on five days. The percentage recoveries for both components were calculated using the corresponding regression equations and they were satisfactory. The percentage relative standard deviation (\% RSD) and percentage relative error (\% Er) did not exceed $2.0 \%$ proving the high repeatability and accuracy of the developed method \% indicating that the developed method was accurate for the determination of OFL and CEF in pharmaceutical formulation.

\section{Robustness and Ruggedness}

As per $\mathrm{ICH}$ guidelines, small, but deliberate variations in concentration of the mobile phase were made to check the accuracy of the method. These variations did not cause any significant difference in the resolution of HPLC method.

\section{Analysis of the Pharmaceutical Dosage Form}

The optimized RP-HPLC procedure was applied for the assay of this drug combination in the pharmaceutical formulation available in the local market (Xiomix-O, Azine healthcare Pvt. Ltd.) The active ingredients were extracted with the same solvent used for the preparation of the standard stock solutions, then dilution was made to reach concentration levels within the specified ranges. The active ingredients eluted at their specific retention times and no interfering peaks were observed from any of the inactive ingredients. The photodiode array detection enabled peak purity verification where no signs of coelution from any of the inactive components were detected. Recoveries were calculated using both external standard and standard addition methods. The assay results of OFL-CEF laboratory-prepared mixtures and pharmaceutical preparation revealed satisfactory accuracy and precision as indicated from \% recovery, SD, and RSD\% values. 


\section{Stability Studies}

\section{Stability study and Force degradation}

The purpose of the stability or degradation study was to ensure the peak purity of the OFL and CEF in the presence of degradation products and establish the stability indicating ability of the method. Under basic, acidic, peroxide and thermal degradation conditions. Studies were performed at $20 \mu \mathrm{g} / \mathrm{ml}$ concentration of OFL and CEF on tablets to provide an indication of the stability-indicating property and specificity of proposed method. By using UV/Visible detector, peak purity test was carried out for the OFL and CEF peaks on samples. All the solutions were prepared by dissolving the drug product in small volume of stressing agents. After degradation, these solutions were diluted with diluent to yield stated OFL and CEF concentration of about 20 $\mu \mathrm{g} / \mathrm{ml}$. Conditions employed for performing the stress studies were as follows (Samanthula et al., 2013; Roy et al., 2013 and Awzalewski et al., 2014)

\section{Base Degradation}

Tablet powder equivalent to $20 \mathrm{mg}$ of OFL and CEF was accurately weighed and dissolved in $20 \mathrm{ml}$ of diluent, added $5 \mathrm{ml} 0.05 \mathrm{~N} \mathrm{NaOH}$ and the mixture was kept at $70^{\circ} \mathrm{C}$ for $1 \mathrm{~h}$. The solution was brought to ambient temperature, neutralized by addition of $5 \mathrm{ml} 0.1 \mathrm{~N} \mathrm{HCl}$ and diluted to $100 \mathrm{ml}$ with diluent. $5 \mathrm{ml}$ of this solution was diluted to $50 \mathrm{ml}$ with diluent.

\section{Acid Degradation}

Tablet powder equivalent to $20 \mathrm{mg}$ of OFL and CEF was accurately weighed and dissolved in $20 \mathrm{ml}$ of diluent, added $5 \mathrm{ml} 0.1 \mathrm{~N} \mathrm{HCl}$ and the mixture was kept at $70^{\circ} \mathrm{C}$ for $1 \mathrm{~h}$. The solution was brought to ambient temperature, neutralized by addition of $5 \mathrm{ml} 0.05 \mathrm{~N} \mathrm{NaOH}$ and diluted to $100 \mathrm{ml}$ with diluent. $5 \mathrm{ml}$ of this solution was diluted to $50 \mathrm{ml}$ with diluent.

\section{Oxidative Degradation}

Tablet powder equivalent to $20 \mathrm{mg}$ of OFL and CEF was accurately weighed and dissolved in $20 \mathrm{ml}$ of diluent, added $5 \mathrm{ml}$ of $1 \%$ hydrogen peroxide. The mixture was kept at room temperature for $1 \mathrm{~h}$ and diluted to $100 \mathrm{ml}$ with diluent. $5 \mathrm{ml}$ of this solution was diluted to $50 \mathrm{ml}$ with diluent.

\section{Hydrolytic Degradation}

Tablet powder equivalent to $20 \mathrm{mg}$ of OFL and CEF was accurately weighed and dissolved in $15 \mathrm{ml}$ of diluent, added $15 \mathrm{ml}$ of water and the mixture was kept at $70^{\circ} \mathrm{C}$ for $24 \mathrm{~h}$. The solution was brought to ambient temperature and diluted to $100 \mathrm{ml}$ with diluent. $5 \mathrm{ml}$ of this solution was diluted to $50 \mathrm{ml}$ with diluent.

\section{Thermal Degradation}

Tablet powder equivalent to $20 \mathrm{mg}$ of OFL and CEF was stored at $100^{\circ} \mathrm{C}$ for $12 \mathrm{~h}$, dissolved and diluted to 100 $\mathrm{ml}$ with diluent. $5 \mathrm{ml}$ of this solution was diluted to $50 \mathrm{ml}$ with diluent.

\section{RESULTS AND DISCUSSION}

\section{Method Development and Optimization}

The objective of the chromatographic method was to separate and quantitate OFL and CEF in presence of degradation products. Two component formulations have gained a lot of importance as there is greater patient acceptability, increased potency and decreased side effect. A calibration curve was plotted for the OFL and CEF range of $5-25 \mu \mathrm{g} / \mathrm{ml}$ for both to allow an assessment of the assay and the plot equation was used for quantization. On the optimization of gradient programme, OFL and CEF peaks were well resolved form degradation products. Based on these experiments, the final optimized conditions are described below. Detection wavelength was selected by overlain spectra at $276 \mathrm{~nm}$. The injection volume was $20 \mu \mathrm{l}$. The typical retention time of OFL and CEF 4.658 and $2.692 \mathrm{~m}$ (Figure 2). The regression value, intercept values, determination coefficient $\left(R^{2}\right)$ and the $\%$ RSD were evaluated. The limits of detection (LODs) and quantitation (LOQs) were determined $(n=6)$ by successive dilutions of the lowest calibration plot point. Repeatability and intermediate precision for OFL and CEF solutions $(n=6)$ were performed in six days and by a single analyst. Recovery was determined through the addition of OFL and CEF at 50,75, 100, 125 and $150 \%$ to a tablet formulation using methanol: phosphate buffer (50:50). The robustness was verified through variation in the mobile phase and flow rate for OFL and CEF standard and tablet solutions at $10 \mu \mathrm{g} / \mathrm{ml}(\mathrm{n}=6)$ (Figure 2).

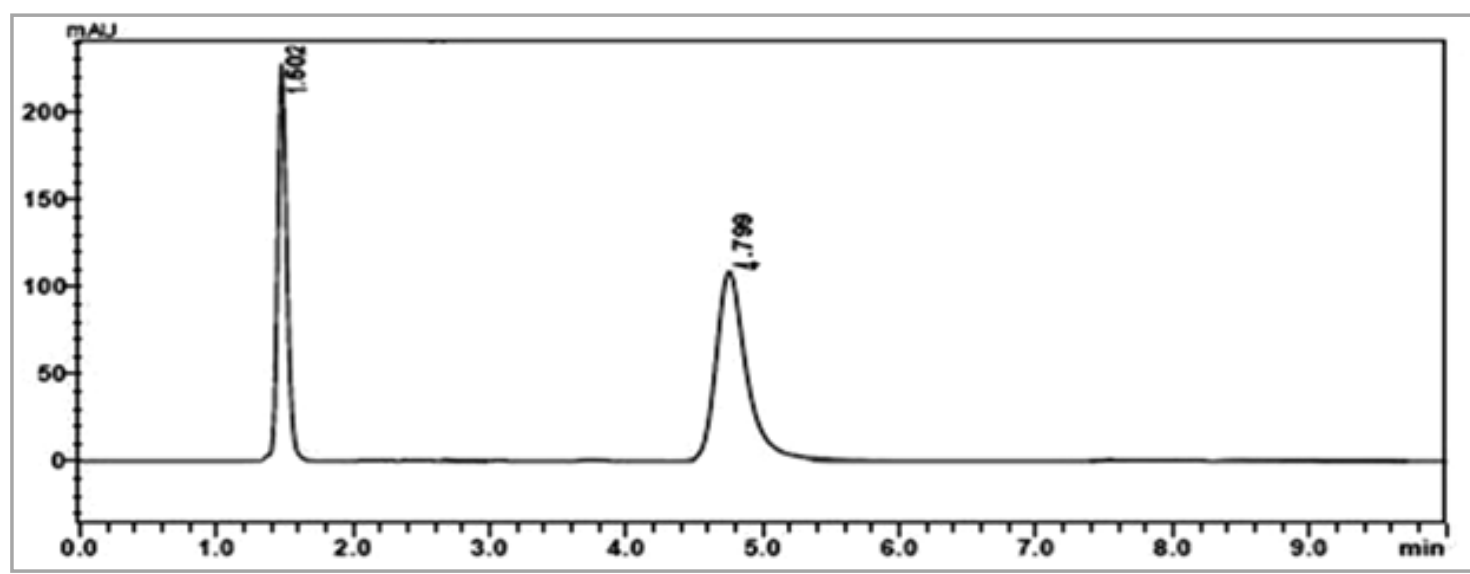

Figure 2: Preliminary chromatograms of OFL and CEF solution prepared in methanol: phosphate buffer (50:50) as the mobile phase $\left(1.0 \mathrm{ml} / \mathrm{min}, \mathrm{C} 18-\mathrm{ODS}\right.$ column $\left(250 \times 4.6 \mathrm{~mm}, 40^{\circ} \mathrm{C}, 20 \mu \mathrm{L}\right)$.

\section{Validation of the Method}

Result shows that an excellent correlation existed between peak area and concentration of OFL and CEF. The linearity range was found to be $5-25 \mu \mathrm{g} / \mathrm{ml}$ for both drug and data was shown in Table 1. The LOD values were 0.0259 and $0.0206 \mu \mathrm{g} / \mathrm{ml}$ and $\mathrm{LOQ}$ values were 0.0787 and $0.0625 \mu \mathrm{g} / \mathrm{ml}$ for OFL and CEF, respectively and shown in table 2. For the determination of accuracy, 
Niurati Jain et al.,

the sample was spiked with standard and \% recovery was calculated. The method was found to be accurate and precise and data was shown in Table 3. Table 4 shows the robustness with respect to change in ratio of mobile phase. The assay results of OFL-CEF laboratoryprepared mixtures and pharmaceutical preparation revealed satisfactory accuracy and precision as indicated from \% recovery, SD, and RSD\% values and data was shown in Table 5 and 6 . It is evident from these results that the proposed method is applicable to the assay of this drug combination with a satisfactory level of selectivity, accuracy, and precision.

Table 1: System suitability parameters

\begin{tabular}{lll}
\hline Parameters & OFL & CEF \\
\hline Calibration range $(\mu \mathrm{g} / \mathrm{ml})$ & $5-25$ & $5-25$ \\
Retention time $(\mathrm{min})$ & 4.799 & 1.602 \\
$\mathrm{~K}$ & 4.09 & 1.32 \\
$\mathrm{~T}_{\mathrm{f}}$ & 1.57 & 1.83 \\
$\mathrm{~A}_{\mathrm{s}}$ & 1.18 & 1.27 \\
Resolution & 4.85 & 2.73 \\
\hline
\end{tabular}

Sci. Technol. Arts Res. J., Oct-Dec 2014, 3(4): 93-98

Table 2: Evaluation of linearity data, LOD and LOQ

\begin{tabular}{lcc}
\hline \multicolumn{1}{c}{ Parameters } & OFL & CEF \\
\hline Detection wavelength $(\mathrm{nm})$ & 276 & 276 \\
Linearity range $(\mu \mathrm{g} / \mathrm{ml})$ & $5-25$ & $5-25$ \\
Correlation coefficient & 0.99706 & 0.9970 \\
Intercept & 150577 & 250577 \\
Slope & 99101 & 99101 \\
Detection limit $(\mu \mathrm{g} / \mathrm{ml})$ & 0.0259 & 0.0206 \\
Quantitation limit $(\mu \mathrm{g} / \mathrm{ml})$ & 0.078 & 0.062 \\
\hline
\end{tabular}

CEF and OFL were found unstable under acidic, basic, peroxide, aqeous and thermal condition and degraded slightly under thermal degradation. Peak purity test was carried out for the OFL and CEF peak by using UV/Visible detector in stress samples analysis. CEF was found stable but OFL degrades significantly. The purity angle was within the purity threshold limit in all of the stressed samples, demonstrating the homogeneity of the peaks. A summary data of stress study is shown in Table 7 and chromatogram shown in Figure 3a-3e.

Table 3: Precision and accuracy for the determination of OFL and CEF in bulk form using the RP-HPLC method

\begin{tabular}{cccccccc}
\hline \multirow{2}{*}{ Analyte } & $\begin{array}{c}\text { Nominal } \\
\text { Value } \\
(\boldsymbol{\mu} \mathbf{g} / \mathbf{m l})\end{array}$ & $\begin{array}{c}\text { \% Estimated } \\
\mathbf{\pm} \% \text { SD }^{\mathbf{a}}\end{array}$ & \%RSD & \%Er & $\begin{array}{c}\text { \%Estimated } \\
\mathbf{\%} \text { I SD }\end{array}$ & $\%$ RSD & $\% \mathrm{Er}$ \\
\hline \multirow{6}{*}{ OFL } & 50 & $49 \pm 0.42$ & 0.86 & -2.0 & $49.3 \pm 0.51$ & 1.03 & -1.40 \\
& 75 & $76.1 \pm 0.90$ & 1.18 & 1.46 & $74.2 \pm 0.89$ & 1.19 & -1.07 \\
& 100 & $100.18 \pm 1.63$ & 1.63 & 0.18 & $99.1 \pm 1.1$ & 1.11 & -0.9 \\
& 125 & $125.4 \pm 0.81$ & 0.65 & 0.32 & $124.2 \pm 1.3$ & 1.05 & -0.81 \\
& 150 & $149.4 \pm 0.32$ & 0.21 & -0.4 & $148.1 \pm 0.42$ & 0.28 & -1.27 \\
& 50 & $49.63 \pm 0.43$ & 0.87 & 0.74 & $49.7 \pm 0.81$ & 1.63 & -0.6 \\
\multirow{6}{*}{ CEF } & 75 & $76.38 \pm 1.16$ & 1.52 & 1.84 & $74.1 \pm 1.1$ & 1.48 & -1.2 \\
& 100 & $100.19 \pm 0.24$ & 0.24 & 0.19 & $100.1 \pm 0.71$ & 0.72 & 0.1 \\
& 125 & $124.07 \pm 0.61$ & 0.49 & -0.81 & $124.3 \pm 0.81$ & 0.65 & -0.56 \\
& 150 & $149.6 \pm 0.42$ & 0.28 & -0.27 & $148.2 \pm 0.32$ & 0.22 & -1.2 \\
\hline
\end{tabular}

Table 4: Robustness result of HPLC method

\begin{tabular}{|c|c|c|c|c|c|c|}
\hline \multirow[t]{2}{*}{ Variation in Chromatographic Condition } & \multicolumn{3}{|c|}{ OFL } & \multicolumn{3}{|c|}{ CEF } \\
\hline & $t \pm \mathrm{SD}^{\mathrm{a}}$ & RSD (\%) & $\operatorname{Er}(\%)$ & $t \pm \mathrm{SD}^{\mathrm{a}}$ & RSD (\%) & $\operatorname{Er}(\%)$ \\
\hline Methanol:phosphate buffer $(60: 40)$ & $4.498 \pm 0.21$ & 0.47 & -6.27 & $1.580 \pm 0.03$ & 1.89 & -1.37 \\
\hline Methanol:phosphate buffer (70:30) & $4.575 \pm 0.01$ & 0.22 & -4.66 & $1.432 \pm 0.02$ & 1.39 & -10.6 \\
\hline Methanol:phosphate buffer (40:60) & $4.698 \pm 0.08$ & 1.70 & -2.10 & $1.421 \pm 0.01$ & 0.70 & -11.3 \\
\hline Flow rate $1.5 \mathrm{ml} / \mathrm{min}$ & $4.632 \pm 0.10$ & 2.26 & -3.47 & $1.692 \pm 0.01$ & 0.59 & 5.61 \\
\hline Flow rate $1.1 \mathrm{ml} / \mathrm{min}$ & $4.610 \pm 0.03$ & 0.68 & -3.93 & $1.542 \pm 0.02$ & 1.29 & -3.74 \\
\hline Flow rate $1.8 \mathrm{ml} / \mathrm{min}$ & $4.532 \pm 0.09$ & 2.07 & -5.56 & $1.367 \pm 0.03$ & 2.19 & -14.7 \\
\hline
\end{tabular}

Table 5: Determination of OFL-CEF laboratory-prepared mixtures using the proposed RP-HPLC method

\begin{tabular}{cccccccc}
\hline \multicolumn{2}{c}{ Nominal value $(\boldsymbol{\mu g} / \mathbf{m l})$} & \multicolumn{2}{c}{ Found $\pm \mathbf{S D}^{\mathbf{a}}(\boldsymbol{\mu g} / \mathbf{m l})$} & \multicolumn{2}{c}{ RSD $(\%)$} & \multicolumn{2}{c}{ Er $(\%)$} \\
\hline OFL & CEF & OFL & CEF & OFL & CEF & OFL & CEF \\
\hline 25 & 25 & $24.78 \pm 0.41$ & $25.08 \pm 0.44$ & 1.65 & 1.75 & -0.88 & 0.32 \\
25 & 75 & $24.89 \pm 0.06$ & $74.89 \pm 0.36$ & 0.24 & 0.48 & -0.44 & -0.15 \\
50 & 25 & $49.34 \pm 0.76$ & $24.78 \pm 0.25$ & 1.54 & 1.00 & -1.32 & -0.88 \\
50 & 50 & $48.87 \pm 0.45$ & $49.54 \pm 0.38$ & 0.92 & 0.76 & -2.26 & -0.92 \\
75 & 25 & $76.02 \pm 0.43$ & $24.81 \pm 0.31$ & 0.56 & 1.24 & 1.36 & 0.76 \\
\hline
\end{tabular}

Table 6: Analysis of OFL-CEF mixture in its pharmaceutical preparation by the proposed RP-HPLC method

\begin{tabular}{lllll}
\hline & \multicolumn{2}{l}{ External standard } & \multicolumn{2}{c}{ Standard addition } \\
\hline & OFL & CEF & OFL & CEF \\
$\%$ Recovery & 100.02 & 99.87 & 98 & 99.26 \\
\pm SD & 0.41 & 0.10 & 0.42 & 0.81 \\
$\%$ RSD & 0.01 & 0.20 & 0.86 & 1.63 \\
\hline
\end{tabular}


Table 7: Summary of forced degradation results

\begin{tabular}{lcccc}
\hline \multicolumn{1}{c}{ Stress condition } & \multicolumn{2}{c}{ OFL } & \multicolumn{2}{c}{ CEF } \\
\cline { 2 - 5 } & \% Degradation & Purity Threshold & \% Degradation & Purity Threshold \\
\hline Base hydrolysis $0.05 \mathrm{~N} \mathrm{NaOH}$ at $70^{\circ} \mathrm{C}, 1 \mathrm{~h}$ & 10.4 & 0.257 & 3.8 & 0.098 \\
Acid hydrolysis $0.1 \mathrm{~N} \mathrm{HCl}$ at $70^{\circ} \mathrm{C}, 1 \mathrm{~h}$ & 18.4 & 0.209 & 6.5 & 0.089 \\
Oxidation $1 \% \mathrm{H} 2 \mathrm{O} 2$ at $\mathrm{RT}, 1 \mathrm{~h}$ & 17.9 & 0.202 & 3.3 & 0.059 \\
Hydrolytic Water at $70^{\circ} \mathrm{C}, 1 \mathrm{~h}$ & 5.6 & 0.212 & 8.2 & 0.089 \\
Thermal $100^{\circ} \mathrm{C}, 12 \mathrm{~h}$ & 11.5 & 0.209 & 0.9 & 0.026 \\
\hline
\end{tabular}
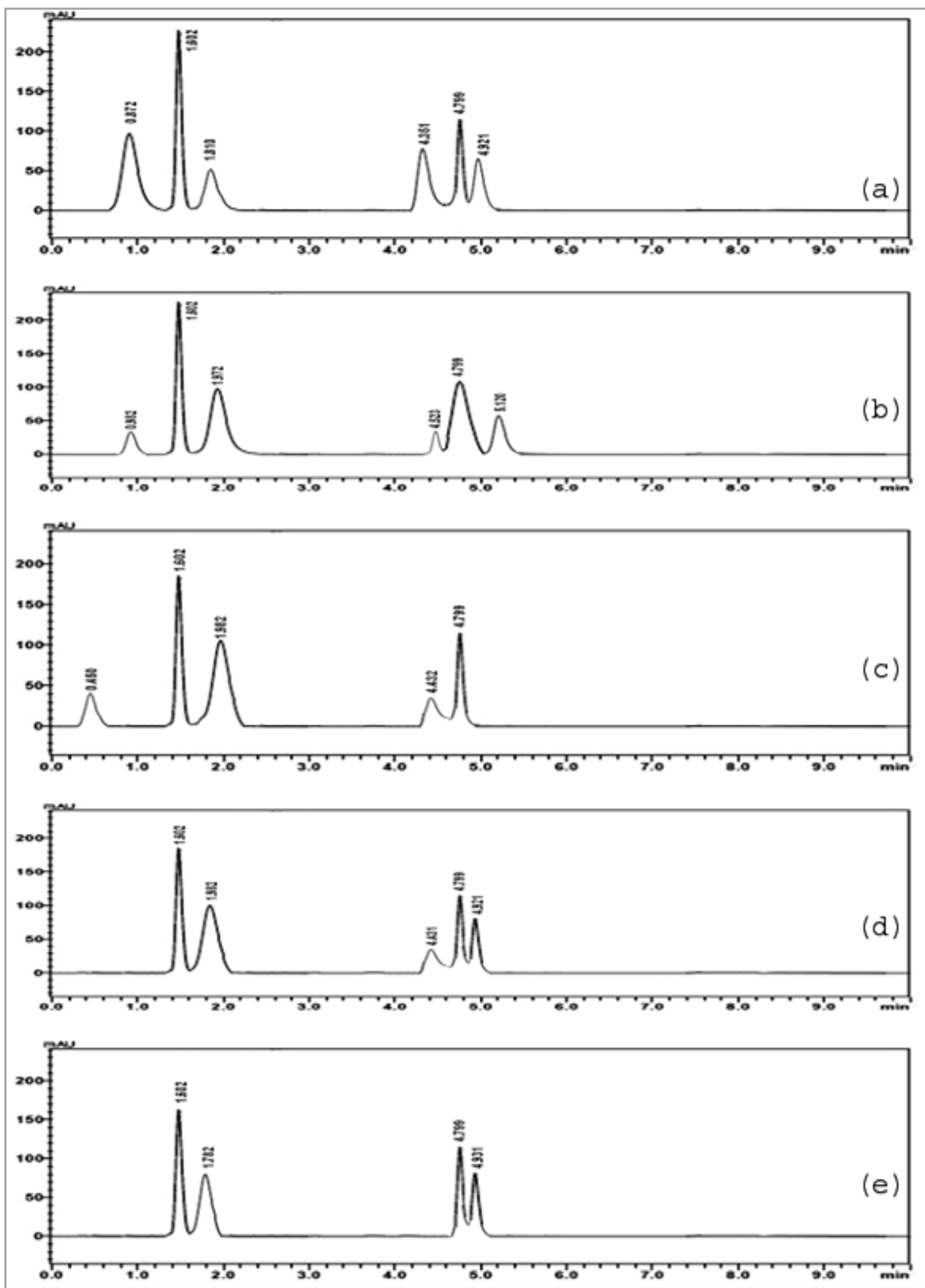

Figure 3: Degradation chromatogram, Alkaline Hydrolytic (3a), Acid Hydrolytic (3b), oxidative (3c), hydrolytic (3d), Thermal (3e) of OFL-CEF 


\section{CONCLUSIONS}

A simple and efficient reverse-phase HPLC method was developed and validated for quantitative determination of OFL and CEF in pharmaceutical dosage forms. The method found to be precise, accurate, linear, robust and rugged during validation. Satisfactory results were obtained from the validation of the method. The purity of both analytes was unaffected by the presence of degradation products and thus confirms the stabilityindicating power of the developed method. The method is stability indicating and can be used for routine analysis of production samples.

\section{ACKNOWLEDGEMENTS}

The authors wish to express their gratitude to Manpur, Dist. Bhind, for the samples of pure OFL and CEF. I would like to thank ADINA Institute of Pharmaceutical Sciences, Sagar (M.P), India for providing facilities to carry out this work.

\section{REFERENCES}

Ali Ahmed, S.M., Elbashir, A.A., Suliman, F.E. and AboulEnein, H.Y. (2013). New spectrofluorimetric method for determination of cephalosporins in pharmaceutical formulations. Luminescence 28: 734-741.

Awzalewski, P., skibi ski, R., cielecka-piontek, J. and Jednarek-Rajewska, K. (2014). Development and validation of stability-indicating HPLC method for determination of cefpirome sulfate. Acta Poloniae Pharmaceutica n Drug Research 71(5): 731-736.

Chopra, I. and Roberts, M. (2001). Tetracycline Antibiotics: Mode of Action, Applications, Molecular Biology, and Epidemiology of Bacterial Resistance. Microbiology and Molecular Biology Reviews 65(2): 232-260.

Deekonda, P. and Reddy, M.S. (2014) Method development and validation for the quantitative estimation of cefixime and ofloxacin in Pharmaceutical preparation by RPHPLC. Der Pharma Chemica 6(2):31-37.

Elbashir, A.A., Ahmed, S.M. and Aboul-Enein, H.Y. (2012). New spectrofluorimetric method for determination of cephalosporins in pharmaceutical formulations. Journal of Fluorescence 22: 857-64.

Hubicka, U., Zmudzki, P., Zuromska-Witek, B., Zajdel, P., Pawłowski, M. and Krzek, J. (2013). Separation and characterization of ciprOFL, difloxacin, lomefloxacin, norfloxacin, and OFL oxidation products under potassium permanganate treatment in acidic medium by UPLCMS/MS. Talanta 109: 91-100.

Khan, A., Iqbal, Z., Khan, M.I., Javed, K., Khan, A., Ahmad, L., Shah, Y. and Nasir, F. (2011). Simultaneous determination of cefdinir and CEF in human plasma by RP-HPLC/UV detection method: Method development, optimization, validation, and its application to a pharmacokinetic study. Journal of Chromatography. B, Analytical Technologies in the Biomedical and Life Sciences 15(879): 2423-2429.

Lalitha Devi, M. and Chandrasekhar, K.B. (2009). A validated stability-indicating RP-HPLC method for levOFL in the presence of degradation products, its process related impurities and identification of oxidative degradant.
Journal of Pharmaceutical and Biomedical Analysis 5(50): 710-7.

Nemutlu, E., Kir, S., Katlan, D. and Beksaç, M.S. (2009). Simultaneous multiresponse optimization of an HPLC method to separate seven cephalosporins in plasma and amniotic fluid: application to validation and quantification of cefepime, CEF and cefoperazone. Talanta 15(80): 11726.

Olsen, B., Lan, P.T., Golparian, D., Johansson, E. and Khang, T.H. (2013). Unemo M. Antimicrobial susceptibility and genetic characteristics of Neisseria gonorrhoeae isolates from Vietnam. BMC Infectious Disease 13: 40.

Ozyüncü, O., Beksac, M.S., Nemutlu, E., Katlan, D. and Kir, S. (2010). Maternal blood and amniotic fluid levels of moxifloxacin, Levofl and CEF. Journal of Obstetrics Gynaecology Research 36(3):484-7.

Patel S.A. and Patel N.J. (2011). Development and Validation of RP-HPLC Method for Simultaneous Estimation of Cefixime Trihydrate and Ofloxacin in Tablet. International Journal of PharmTech Research 3: 1958-1962.

Pulgarín, J.A., Molina, A.A. and Boras, N. (2013). Development of a spectrofluorimetric method for the determination of OFL in urine. Applied Spectroscopy 67: 1029-35.

Roy, C. and Chakrabarty, J. (2013). Development and Validation of a Stability-Indicating RP-HPLC Method for the Simultaneous Determination of Phenoxyethanol, Methylparaben, Propylparaben, Mometasone Furoate, and Tazarotene in Topical Pharmaceutical Dosage Formulation. Scientia Pharmaceutica 81: 951-967.

Samanthula, G., Yadiki, K., Saladi, S.,Gutala, S. and Surendranath, K.V. (2013). Stability-Indicating RP-HPLC Method for the Simultaneous Estimation of Doxofylline and Terbutalinesulphate in Pharmaceutical Formulations. Scientia Pharmaceutica 81: 969-982.

Sethi, S., Golparian, D., Bala, M., Dorji, D., Ibrahim, M., Jabeen, K. and Unemo, M. (2013). Antimicrobial susceptibility and genetic characteristics of Neisseria gonorrhoeae isolates from India, Pakistan and Bhutan in 2007-2011. Bio Med Central Infectious Disease 24(13): 35.

Shervington, L.A., Abba, M., Hussain, B. and Donnelly, J. (2005). The simultaneous separation and determination of five quinolone antibiotics using isocratic reversed-phase HPLC: application to stability studies on an OFL tablet formulation. Journal of Pharmaceutical and Biomedical Analysis 15(39): 769-775.

Veziris, N., Chauffour, N., Escolano, N., Henquet, N., Matsuoka, N., Jarlier, N. and Aubry, A. (2013). Resistance of $M$. leprae to Quinolones: A Question of Relativity?. PLoS Neglected Tropical Diseases 7: 2559.

Yoon, H.I., Lee, C.H., Kim, D.K., Park, G.M., Lee, S.M., Yim, J.J., Kim, J.Y., Lee, J.H., Lee, C.T., Chung, H., Kim, Y.W., Han, S.K. and Yoo, C.G. (2013). Efficacy of levOFL versus cefuroxime in treating acute exacerbations of chronic obstructive pulmonary disease. International Journal of Chronic Obstructive Pulmonary Disease 8: 329-334. 